\title{
Editorial
}

\section{Using Alcohol for Hand Antisepsis: Dispelling Old Myths}

\author{
John M. Boyce, MD
}

I have taken the unusual step of requesting an editorial from an author of the article being discussed in order to offer an opportunity to place the issues addressed herein in a larger context. A dispute has simmered for more than a decade as to the appropriate role (if any) of waterless hand cleansers, with most American authorities skeptical and European authorities supportive. However, considerable evidence has accumulated in the past few years, as reviewed below by an American expert, and there may no longer be room for dispute- $\mathrm{ED}$.

Alcohol has been used as an antiseptic since ancient times. However, the first systematic in vitro studies of the germicidal activity of ethyl alcohol against pure cultures of bacteria were performed by Koch in the early $1880 \mathrm{~s}^{1}{ }^{1}$ In the 1890 s and early 1900 s, alcohol was proposed for use as a skin antiseptic. ${ }^{1}$ Early investigators discovered that alcohols must be diluted with water for maximal antimicrobial activity and that preparations containing $50 \%$ to $70 \%$ alcohol were more effective than $95 \%$ alcohol. ${ }^{1,2}$ In 1922 , studies in Germany demonstrated the efficacy of an isopropyl alcohol hand rub in reducing bacterial counts on contaminated hands. ${ }^{3}$ In 1935 , isopropyl alcohol was added to the American Medical Association Council on Pharmacy and Chemistry's list of new and nonofficial remedies, and disinfection of the skin was listed as one of its recommended uses. ${ }^{4}$ Using more quantitative methods, Price showed in the late 1930 s that $65.5 \%$ alcohol was effective in reducing the number of bacteria on the skin. ${ }^{1}$ He subsequently recommended the use of a 3-minute wash with $70 \%$ alcohol as a preoperative hand scrub and that $70 \%$ alcohol should be used for disinfecting contaminated hands. ${ }^{1}$

Despite these early studies, in 1961, public health authorities in the United States produced a training film that claimed that mechanical removal of organisms by washing hands with soap and water was more effective than using a chemical antiseptic. ${ }^{5}$ However, this concept has subsequently been shown in multiple studies to be untrue. For example, some of the first commercial alcohol- based preoperative hand-rub preparations introduced in the 1960 s were found to be more effective than surgicalscrub protocols using antimicrobial soaps containing hexachlorophene or iodophors. ${ }^{6-8}$

Numerous subsequent studies have confirmed that $60 \%$ to $70 \%$ alcohol solutions reduce bacterial counts on the hands of healthcare workers significantly better than washing hands with plain soap and water and are as effective or more effective than hand washing with an antimicrobial soap. ${ }^{7,9-16}$ If used for preoperative hand scrubs by surgeons, alcohol preparations reduce bacterial counts on hands more effectively than plain soap or antimicrobial soap. ${ }^{16-20}$ In one study where healthcare workers contaminated their hands by touching a heavily colonized patient, hand antisepsis with a $70 \%$ isopropyl alcohol preparation prevented transfer of organisms from the hands of personnel to a catheter more effectively than hand washing with plain soap and water. ${ }^{21}$

The bactericidal activity of alcohols is most likely due to their ability to denature proteins. ${ }^{22}$ Alcohols are effective against most vegetative gram-positive and gram-negative bacteria. A few studies suggest that alcohol-containing products may have greater activity than antiseptic detergents against multidrug-resistant pathogens such as vancomycin-resistant enterococci and methicillin-resistant Staphylococcus aureus, but additional evidence on this issue is needed. ${ }^{23-25}$ Alcohols have excellent activity against Mycobacterium tuberculosis, but are not active against bacterial spores. They do have activity against many fungi and a variety of viruses, including hepatitis $B$, human immunodeficiency virus, enteroviruses, adenovirus, rotaviruses, and herpes simplex virus. ${ }^{22}$ Ethyl alcohol is more active than isopropyl alcohol against many viruses, except those with a lipid envelope.

Despite the proven efficacy of alcohol-based products, delayed acceptance of alcohol hand antisepsis by hos-

From the Division of Infectious Diseases, Hospital of Saint Raphael, New Haven, Connecticut.

Address reprint requests to John $M$. Boyce, MD, Division of Infectious Diseases, Hospital of Saint Raphael, 1450 Chapel St, New Haven, CT 06511. OO-ED-084. Boyce JM. Using alcohol for hand antisepsis: dispelling old myths. Infect Control Hosp Epidemiol 2000;21:438-441. 
pitals in the United States has been attributable in part to a concern among many healthcare personnel that repeated use of alcohol would lead to excessive drying of the skin.7,26 This concept has also been shown not to be true. Numerous investigators have dealt with this issue by incorporating $1 \%$ to $3 \%$ glycerol or other emollients into alcohol hand rinses or gels to help reduce skin dryness. 7,9,12,17,27-29 Several studies have documented that such preparations are well tolerated by healthcare workers. ${ }^{6,18,19,22,30,31}$ Unfortunately, most healthcare workers are not familiar with these studies, and the view that frequent use of alcoholbased hand antiseptics will lead to excessive skin dryness has persisted in many hospitals in the United States.

This issue of Infection Control and Hospital Epidemiology contains our article reporting a prospective randomized trial that compared the frequency of skin irritation and dryness associated with two hand-hygiene regimens: soap-and-water hand washing versus a regimen that called for use of an alcoholic hand gel between most patient contacts. ${ }^{32}$ Several features of the study should make the results clinically relevant. Unlike earlier studies conducted in controlled laboratory settings, ${ }^{12,30}$ participants in the present study were nurses who were performing standard patient-care activities on several wards. Importantly, the soap preparations used are representative of those available in many acute-care hospitals, since soap products available on the wards were purchased through a hospital buying group that includes approximately 1,800 healthcare facilities. The alcoholic hand gel was a commercially available preparation.

Several other aspects of the study are notable. We used both subjective and objective methods to evaluate skin irritation and dryness. Also, by using a crossover design, each nurse served as her or his own control, obviating potential differences in the frequency of preexisting skin problems among individuals in the two arms of the study. Finally, participants were asked to record prospectively the number of hand-hygiene episodes (hand washing or hand antisepsis) during the trial using portable counting devices, a technique seldom used in other published trials.

Self-assessments by participants, visual assessments by a study nurse, and objective measurements of skin hydration revealed that nurses experienced significantly less skin irritation and dryness when using the alcoholic gel regimen than when they were using standard soap-and-water hand washing. ${ }^{32}$ Of interest, the alcoholic gel was tolerated better even though participants used the alcoholic regimen slightly more often than soap and water. The outcome probably can be attributed to several factors. Soap-and-water hand washing tends to wash away skin oils and fats that help protect normal epidermis, whereas this is less likely to occur with a waterless antiseptic like alcohol. Skin damage related to use of hot water, and perhaps due to use of paper towels, does not occur with waterless antiseptic agents. Also, like other commercially produced alcohol-based hand gels and rinses, the product tested in the trial contains skinconditioning agents, humectants, and an emollient that are added to minimize the drying effect of alcohol.
Our study has several shortcomings. The number of participants in the trial was small $(n=29)$, and personnel from only three areas of the hospital were included. Also, the two regimens were each used for only 2 weeks. Additional studies with larger sample sizes and longer trial periods are needed to determine if the findings will hold true over months or years. Although use of selfassessments by unblinded study participants raises the issue of potential observer bias, self-assessments are worth including in such studies because they can provide information about burning sensation or itching of the skin that cannot be evaluated by objective means. ${ }^{33}$ We did not utilize measurements of transepidermal water loss (TEWL), which is considered to be one of the best methods for evaluating skin damage due to chronic irritant contact dermatitis associated with use of soaps and detergents. ${ }^{34,35}$ However, TEWL measurements are quite susceptible to environmental conditions that might be difficult to control on standard hospital wards. Measurement of electrical capacitance of nurses' skin by the investigators was an appropriate method for assessing skin dryness. . $^{34,36,37}$ Finally, we evaluated only one commercially available alcoholic hand gel. Such products vary considerably in their formulation, and it is possible that other alcoholic hand gels or rinses may not have produced the same results. Further studies comparing alcohol-based products and soap-andwater hand washing are warranted.

Another important advantage of alcohol-based hand antiseptics is that their use does not require sinks or plumbing. As a result, alcohol-based products can be placed in many locations on hospital wards. Voss and Widmer noted that it took intensive care unit nurses approximately 60 seconds to go to a sink, wash and dry their hands, and return to patient-care activities, whereas use of an alcohol-based antiseptic available at each patient's bed required only 15 seconds. ${ }^{38}$ This is an important issue since nurses often cite lack of time as one of the greatest deterrents to frequent hand washing. ${ }^{39,40}$ Large-scale observational studies of handwashing compliance by Pittet and colleagues have confirmed that heavy work loads are an independent predictor of poor handwashing compliance. ${ }^{41}$ By reducing the time required for cleaning one's hands and making materials required for hand hygiene available in many locations, compliance of healthcare workers with recommended practices should improve. ${ }^{42,43}$ For example, Pittet et al demonstrated that a multidisciplinary hand-hygiene program that resulted in greater use of an alcoholic hand rinse contributed to improved hand-hygiene compliance in a large university hospital. ${ }^{42}$ of note, these investigators demonstrated that improved hand-hygiene compliance was associated with a significant reduction in the prevalence of nosocomial infections and in the incidence of methicillin-resistant $S$ aureus colonization and infection. In a smaller study conducted in a medical intensive care unit, Bischoff et al found that placing an alcoholbased hand gel next to each patient's bed resulted in improved hand-hygiene compliance. ${ }^{43}$ 
Any discussion of hand antisepsis using alcoholbased products would be incomplete without a few caveats. If hands are visibly dirty or contaminated with appreciable amounts of organic material, it is preferable to wash hands with soap and water, because alcohols are not as effective in this setting. ${ }^{44}$ To be optimally effective for hand antisepsis, an adequate volume of alcohol must be used. Mackintosh found that application of $0.3 \mathrm{~mL}$ to the hands was no more effective than plain soap-and-water hand washing. ${ }^{45}$ Simply increasing the volume to $0.5 \mathrm{~mL}$ increased the effectiveness of alcohols substantially. Larson demonstrated that $1 \mathrm{~mL}$ of alcohol was significantly less effective than applying $3 \mathrm{~mL}$ to the hands. ${ }^{13}$ Failure to cover all surfaces of the hands and fingers also reduces the efficacy of alcohol hand rubs., 946

Moreover, a few issues unique to alcohol-based hand rinses and gels need to be considered by hospitals. For example, alcohol rinses and gels are flammable and need to be stored in areas where the risk of fire or very high temperatures is minimal. This should not be an issue for most facilities. Such products vary considerably with respect to their consistency (feel), fragrance, skin-conditioning agents, propensity to become sticky while drying, and evaporation times. These characteristics can influence acceptance (and use) of the product by health personnel. ${ }^{12}$ Also, if product characteristics are not matched carefully with dispenser design, clogging of dispensers may occur if the product evaporates in the spout of the dispenser. Before installing alcohol dispensers hospitalwide, it may be prudent to place the model of dispenser under consideration in a few locations for a 1- to 2-month trial period to detect any potential problems.

In general, commercially produced alcoholic gels and rinses have been more expensive than non-medicated soaps. Depending on the vendor or contractual agreements, the cost per liter of alcoholic gels and rinses may equal or exceed that of popular antiseptic soaps and detergents. However, administrators should consider that modest increases in acquisition costs for alcohol-based handhygiene products are tiny in comparison to excess hospital costs associated with nosocomial infections. ${ }^{47}$ If increased use of an alcohol gel or rinse reduces the number of serious nosocomial infections by a few per year, the cost savings from prevented infections should more than offset incremental costs of using alcohol-based preparations. Also, the prices of alcoholic hand gels and rinses are likely to decrease as more manufacturers enter the market.

In conclusion, it is time for nursing schools, medical schools, and infection control programs to include material regarding the potential advantages and disadvantages of waterless antiseptic agents in educational programs dealing with hand washing and hand antisepsis. A greater awareness among healthcare workers of alcohol-based waterless antiseptic agents will provide an atmosphere that will foster additional studies that are needed to establish if wider use of such agents will lead to lasting improvements in hand-hygiene practices and to lower rates of nosocomial infections.

\section{REFERENCES}

1. Price PB. Ethyl alcohol as a germicide. Arch Surg 1939;38:528-542.

2. Harrington $\mathrm{C}$, Walker $\mathrm{H}$. The germicidal action of alcohol. Boston Medical and Surgical Journal 1903;148:548-552.

3. Grant DH. The antiseptic and bactericidal properties of isopropyl alcohol. Am J Med Sci 1923;166:261-265.

4. Council on Pharmacy and Chemistry. New and Nonofficial Remedies. Isopropyl alcohol. JAMA 1935;105:1683-1684.

5. Coppage CM. Handwashing in Patient Care. Washington, DC: United States Public Health Service; 1961.

6. Walter CW. Disinfection of hands. Am J Surg 1965;109:691-693.

7. Dineen P, Hildick-Smith G. Antiseptic care of the hands. In: Maibach HI, Hildick-Smith G, eds. Skin Bacteria and Their Role in Infection. New York, NY: McGraw-Hill; 1965:291-309.

8. Berman RE, Knight RA. Evaluation of hand antisepsis. Arch Environ Health 1969;18:781-783.

9. Ayliffe GAJ, Babb JR, Quoraishi AH. A test for "hygienic" hand disinfection. J Clin Pathol 1978;31:923-928.

10. Ojajarvi J. Effectiveness of hand washing and disinfection methods in removing transient bacteria after patient nursing. I Hyg (Camb) 1980;85:193-203.

11. Rotter ML. Hygienic hand disinfection. Infect Control 1984;1:18-22.

12. Larson EL, Eke PI, Laughon BE. Efficacy of alcohol-based hand rinses under frequent-use conditions. Antimicrob Agents Chemother 1986;30:542-544.

13. Larson EL, Eke PI, Wilder MP, Laughon BE. Quantity of soap as a variable in handwashing. Infect Control 1987;8:371-375.

14. Ayliffe GAJ, Babb JR, Davies JG, Lilly HA. Hand disinfection: a comparison of various agents in laboratory and ward studies. J Hosp Infect 1988;11:226-243.

15. Zaragoza M, Salles M, Gomez J, Bayas JM, Trilla A. Handwashing with soap or alcoholic solutions? A randomized clinical trial of its effectiveness. Am I Infect Control 1999;27:258-261.

16. Rotter M. Hand washing and hand disinfection. In: Mayhall CG, ed. Hospital Epidemiology and Infection Control. Philadelphia, PA: Lippincott Williams \& Wilkins; 1999:1339-1355.

17. Bernard E, Knight RA. Evaluation of hand antisepsis. Arch Environ Health 1969;18:781-783.

18. Gravens DL, Butcher HR Jr, Ballinger WF, Dewar NE. Septisol antiseptic foam for hands of operating room personnel: an effective antibacterial agent. Surgery 1973;73:360-367.

19. Lowbury EJL, Lilly HA, Ayliffe GAJ. Preoperative disinfection of surgeon's hands: use of alcoholic solutions and effects of gloves on skin flora. $B M J 1974 ; 4: 369-372$.

20. Larson EL, Butz AM, Gullette DL, Laughon BA. Alcohol for surgical scrubbing? Infect Control Hosp Epidemiol 1990;11:139-143.

21. Ehrenkranz NJ, Alfonso BC. Failure of bland soap handwash to prevent hand transfer of patient bacteria to urethral catheters. Infect Control Hosp Epidemiol 1991;12:654-662.

22. Larson EL, Morton HE. Alcohols. In: Block SS, ed. Disinfection, Sterilization and Preservation. Philadelphia, PA: Lea \& Febiger; 1991:191-203.

23. Wade JJ, Desai N, Casewell MW. Hygienic hand disinfection for the removal of epidemic vancomycin-resistant Enterococcus faecium and gentamicin-resistant Enterobacter cloacae. J Hosp Infect 1991;18:211-218.

24. Kampf G, Hofer M, Wendt C. Efficacy of hand disinfectants against vancomycin-resistant enterococci in vitro. J Hosp Infect 1999;42:143-150.

25. Kampf G, Jarosch R, Ruden H. Limited effectiveness of chlorhexidine based hand disinfectants against methicillin-resistant Staphylococcus aureus (MRSA). J Hosp Infect 1998;38:297-303.

26. Steere AC, Mallison GF. Handwashing practices for the prevention of nosocomial infections. Ann Intern Med 1975;83:683-690.

27. Ojajarvi J, Makela P, Rantasalo I. Failure of hand disinfection with frequent hand washing: a need for prolonged field studies. $J \mathrm{Hyg}$ 1977;79:107-119.

28. Morrison AJ Jr, Gratz J, Cabezudo I, Wenzel RP. The efficacy of several new handwashing agents for removing non-transient bacterial flora from hands. Infect Control 1986;7:268-272.

29. Ojajarvi J. Handwashing in Finland. J Hosp Infect 1991;18:35-40.

30. Newman JL, Seitz JC. Intermittent use of an antimicrobial hand gel for reducing soap-induced irritation of health care personnel. Am J Infect Control 1990;18:194-200.

31. Rotter ML, Koller W, Neumann R. The influence of cosmetic additives on the acceptability of alcohol-based hand disinfectants. J Hosp Infect 1991;18(suppl B):57-63.

32. Boyce JM, Kelliher S, Vallande N. Skin irritation and dryness associated with two hand-hygiene regimens: soap-and-water hand washing versus hand antisepsis with an alcoholic hand gel. Infect Control Hosp Epidemiol 2000;21:442-448. 
33. Simion FA, Rhein LD, Morrison BM Jr, Scala DD, Salko DM, Kligman $\mathrm{AM}$, et al. Self-perceived sensory responses to soap and synthetic detergent bars correlate with clinical signs of irritation. J Am Acad Dermatol 1995;32:205-211.

34. Ollmar S, Nyren M, Nicander I, Lemtestam L. Electrical impedance compared with other non-invasive bioengineering techniques and visual scoring for detection in irritation in human skin. $\mathrm{Br} J$ Dermatol 1994;130:29-36.

35. Wilhelm K-P, Freitag G, Wolff HH. Surfactant-induced skin irritation and skin repair: evaluation of a cumulative human irritation model by noninvasive techniques. J Am Acad Dermatol 1994;31:981-987.

36. Wilhelm K-P, Cua AB, Wolff HH, Maibach HI. Surfactant-induced stratum corneum hydration in vivo: prediction of the irritation potential of anionic surfactants. J Invest Dermatol 1993;101:310-315.

37. Nicander I, Ollmar S, Lundh Rozell B, Eek A, Emtestam L. Electrical impedance measured to five skin depths in mild irritant dermatitis induced by sodium lauryl sulphate. Br J Dermatol 1995;132:718-724.

38. Voss A, Widmer AF. No time for handwashing!? Handwashing versus alcoholic rub: can we afford 100\% compliance? Infect Control Hosp Epidemiol 1997;18:205-208.

39. Larson E, Killien M. Factors influencing handwashing behavior of patient care personnel. Am J Infect Control 1982;10:93-99.

40. Zimakoff J, Kjelsberg AB, Larsen SO, Holstein B. A multicenter questionnaire investigation of attitudes toward hand hygiene, assessed by the staff in fifteen hospitals in Denmark and Norway. Am J Infect Control 1992;20:58-64.

41. Pittet D, Mourouga P, Perneger TV, members of the Infection Control Program. Compliance with handwashing in a teaching hospital. Ann Intern Med 1999;130:126-130.

42. Pittet D, Sauvan V, Perneger TV, and members of the Infection Control Program. Improving compliance with hand hygiene in hospital. In: Program of the Ninth Annual Scientific Meeting of the Society for Healthcare Epidemiology of America. April 18-20, 1999; San Francisco, CA. Abstract 77.

43. Bischoff WE, Reynolds TM, Sessler CN, Edmond MB, Wenzel RP Handwashing compliance by health care workers. Arch Intern Med 2000;160:1017-1021.

44. Larson EL, APIC Guidelines Committee. APIC guideline for handwashing and hand antisepsis in health care settings. Am J Infect Control 1995;23:251-269.

45. Mackintosh CA, Hoffman PN. An extended model for transfer of microorganisms via the hands: differences between organisms and the effect of alcohol disinfection. J Hyg 1984;92:345-355.

46. Taylor LJ. An evaluation of handwashing techniques-1. Nursing Times $1978 ; 54-55$

47. Boyce JM. Antiseptic techology: access, affordability and acceptance. Presented at the 4th Decennial International Conference on Nosocomial and Healthcare-Associated Infections; March 5-9, 2000; Atlanta, GA. 